\title{
Reflets
}

Revue ontaroise d'intervention sociale et communautaire

\section{Le pouvoir des mots}

\section{Smail Gounane}

Volume 4, numéro 2, automne 1998

Personnes vivant avec une incapacité

URI : https://id.erudit.org/iderudit/026236ar

DOI : https://doi.org/10.7202/026236ar

Aller au sommaire du numéro

Éditeur(s)

Reflets : Revue ontaroise d'intervention sociale et communautaire

ISSN

1203-4576 (imprimé)

1712-8498 (numérique)

Découvrir la revue

Citer ce document

Gounane, S. (1998). Le pouvoir des mots. Reflets, 4(2), 207-208.

https://doi.org/10.7202/026236ar

Tous droits réservés (C) Reflets : Revue ontaroise d'intervention sociale et communautaire, 1998

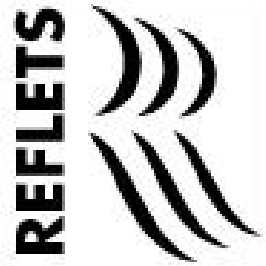

Ce document est protégé par la loi sur le droit d'auteur. L'utilisation des services d'Érudit (y compris la reproduction) est assujettie à sa politique d'utilisation que vous pouvez consulter en ligne.

https://apropos.erudit.org/fr/usagers/politique-dutilisation/ 


\section{Le pouvoir des mots}

Smail Gounane, Toronto

On ne peut imaginer une société humaine sans communication, sans langage. Les moyens de communication sont la base même de toute civilisation. Au fil des siècles, les moyens de communication ont été une arme que les élites ont utilisée pour contrôler leur entourage. Il aura fallu les grands développements technologiques, de la découverte de l'imprimerie à aujourd'hui, pour que les moyens de communication connaissent une certaine démocratisation. Cette dernière permet un accès sans pareil aux médias.Aujourd'hui, personne n'ignore l'importance cruciale des outils de communication que sont les journaux, le radio, la télévision et l'Internet. Ils ont révolutionné notre quotidien. Plus que jamais, il est possible à quiconque le désire, d'utiliser les moyens de communication et ainsi de signifier sa présence dans le village global qui devient chaque jour une réalité.

C'est dans cette perspective que le journal DÉFI a été créé. Combatte l'ignorance et favoriser une meilleure compréhension de la situation des personnes handicapées, sont les raisons d'être de notre journal qui est fait par ces personnes. Nous ne nous posons pas en détenteurs d'une vérité que nous serions les seuls à connaitre, mais nous nous disons que l'expression de la plus grande diversité d'opinions est souhaitable. En effet, chacune d'elles contient sa part de vérité et c'est en les partageant que nous pouvons faire avancer les choses. Notre journal donne la parole à tous, de façon à ce que chacun soit écouté. Nous ne voulons exclure personne, car nous connaissons trop bien le prix de l'exclusion et de toutes les formes de marginalisation.

Les facteurs économiques et politiques sont primordiaux à toute reconnaissance sociale. À cet égard, les personnes handicapées doivent suivre l'exemple de d'autres groupes qui ont réussi à 
s'imposer sur le plan social. Par exemple, les groupes féministes ont fini par venir à bout de la vision patriarcale de la société. Le poids économique et politique des femmes a su surmonter la résistance des acteurs sociaux les plus réticents. Or, les personnes vivant avec un handicap disposent de ces deux facteurs, bien qu'ils restent marginalisés jusqu'à un certain point.

Les besoins des personnes handicapées font vivre des milliers d'entreprises et d'organisations. Elles constituent un énorme marché. De plus, il y a un nombre grandissant de personnes handicapées qui créent leur propre entreprise, notamment dans le domaine de l'informatique ou dans le secteur des services. À ce compte, il ne faut pas négliger également les personnes handicapées qui travaillent dans les différents secteurs économiques et sociaux. Le pouvoir d'achat de certains d'entre eux devient plus important et est appelé à s'accroître davantage avec le vieillissement des «baby boomers» et le nombre croissant de personnes ayant une incapacité. Tous témoignent de la force économique dont disposent les personnes handicapées. Par ailleurs, elles forment un électorat important si on ajoute à leur nombre, celui de leurs familles et de leurs amis.

Les politiciens et les hommes d'affaires ne peuvent plus ignorer ce potentiel économique et politique grandissant. Cela dit, un grand nombre de personnes handicapées qui sont réduites au chômage ou qui ne peuvent pas travailler, ont des conditions de vie qui les situent bien en dessous du seuil de pauvreté. Pour eux, on doit revoir leurs allocations mensuelles afin que celles-ci couvrent leurs besoins spéciaux.

DÉFI soulève ce besoin urgent de dire et refléter une réalité sociale avec toutes ses contradictions. Il importe de dire que chaque vie contient son lot de joies et d'espoirs, mais aussi son lot de détresse et de précarité. Il nous faut combatte ces dernières sur tous les fronts, y compris sur le plan intellectuel, car toute forme de discrimination qu'elle soit économique, politique ou sociale est avant tout le fruit de l'ignorance.

Le journalisme est un moyen idéal pour changer les choses, car les mots ont un pouvoir certain. Et s'il s'agit d'un changement positif, alors nous sommes du voyage. 